\title{
DE LA DIFICULTAD CONTRAMAYORITARIA AL DIÁLOGO INTERINSTITUCIONAL: MECANISMOS DE EQUILIBRIO EN LA RELACIÓN JUSTICIA CONSTITUCIONAL - PODER LEGISLATIVO
}

\section{From the counter-majoritarian difficulty to an interinstitutional dialogue: Mechanisms of balance in the relationship between judicial review and the legislature}

\author{
ALBERTO MACHO CARRO' \\ Universidad de Valladolid \\ albertojavier.macho@uva.es
}

Cómo citar/Citation

Macho Carro, A. (2019).

De la dificultad contramayoritaria al diálogo interinstitucional: mecanismos de equilibrio en la relación justicia constitucional - Poder Legislativo.

Anuario Iberoamericano de Justicia Constitucional, 23(1), 231-260.

doi: https://doi.org/10.18042/cepc/aijc.23.08

\section{Resumen}

Este artículo parte de la denominada dificultad contramayoritaria con el propósito de estudiar algunos mecanismos concretos que han ido surgiendo en el derecho comparado y que podrían servir para superarla. En este sentido, tras una breve in-

1 Investigador predoctoral de la Junta de Castilla y León en el área de Derecho Constitucional de la Universidad de Valladolid. Exbecario del Servicio de Doctrina del Tribunal Constitucional. Máster en Derecho Constitucional por el Centro de Estudios Políticos y Constitucionales y la UIMP. Graduado en Derecho y ADE por la Universidad de Valladolid. 
cursión en los conceptos de «constitucionalismo dialógico» $\mathrm{y}$ «new Commonwealth constitutionalism», el trabajo pone en relación la cláusula «no-obstante» de la Constitución canadiense con ciertas modalidades de sentencias constitucionales que han ido adoptándose en Europa en las últimas décadas, en el entendido de que, aunque diferentes, ambos constituyen mecanismos jurídicos que permiten tanto soslayar aquella dificultad como clarificar el papel que la justicia constitucional debe ocupar en un nuevo contexto de división de poderes.

\title{
Palabras clave
}

Objeción contramayoritaria; constitucionalismo dialógico; new Commonwealth constitutionalism; cláusula no-obstante; efectos de las sentencias constitucionales.

\begin{abstract}
The launching pad of this paper is the so-called counter majoritarian difficulty, and its aim is to look into some particular mechanisms found in comparative law which could overcome it. In this sense, after a brief incursion into the concepts of "dialogic constitutionalism" and "new Commonwealth constitutionalism", the article relates the notwithstanding clause in the Canadian constitution with some types of constitutional rulings that have been being passed in Europe over the last decades. The idea is that, by different means, both mechanisms allow both to overcome the above mentioned difficulty and to clarify the role that judicial review must play in a new context of division of powers.
\end{abstract}

\section{Keywords}

Counter-majoritarian difficulty; dialogic constitutionalism; new Commonwealth constitutionalism; notwithstanding clause; effects of constitutional rulings. 


\section{SUMARIO}

I. INTRODUCCIÓN. II. LA DIFICULTAD CONTRAMAYORITARIA. III. CONSTITUCIONALISMO DIALÓGICO Y NEW COMMONWEALTH CONSTITUTIONALISM. IV. LA CLÁUSULA NOTWITHSTANDING DE LA CONSTITUCIÓN CANADIENSE. V. LAS POSIBLES TÉCNICAS DIALÓGICAS DEL CONTROL DE CONSTITUCIONALIDAD EN EUROPA: 1. La anulación diferida y el reenvío legislativo en Austria. 2. La inconstitucionalidad sin nulidad en Alemania. VI. LAS POSIBILIDADES DE DIÁLOGO INTERINSTITUCIONAL Y LOS MECANISMOS DE EQUILIBRIO EN ESPAÑA VII. CONCLUSIONES. BIBLOGRAFÍA.

\section{INTRODUCCIÓN}

Con su trabajo Justicia constitucional y democracia, Víctor Ferreres (2007) importó el debate norteamericano sobre la justificación y los límites del control judicial de la ley a la academia hispana, que empezaría a prestar atención a la llamada dificultad contramayoritaria.

El presente estudio no pretende ser una aportación teórica más a esta discusión, ya suficientemente prolija. Lo que pretendemos aquí es analizar algunos mecanismos jurídicos concretos de derecho comparado que permitirían aliviar una tensión hasta ahora considerada congénita a toda democracia constitucional. Para ello, lo primero que haremos será explicar brevemente en qué consiste dicha objeción contramayoritaria. A continuación, efectuaremos una somera referencia al denominado constitucionalismo dialógico, pues las diversas propuestas englobadas bajo dicha categoría aspiran a establecer un nuevo modelo de relación entre la justicia constitucional y el legislador basado en una suerte de diálogo que, aparentemente, dejaría atrás aquella tensión. Veremos en qué consiste dicho diálogo y si es cierto que el mismo se circunscribe a los sistemas jurídicos de tradición británica, que tendrían en Canadá su más precoz representante, lo que nos llevará a estudiar su famosa «cláusula no-obstante». Tras esta incursión en el modelo Commonwealth, comprobaremos si el recurso a determinadas modalidades de pronunciamientos constitucionales en Europa — las llamadas «sentencias bilaterales»— permite también suavizar la referida tensión, y propiciar igualmente una relación dialógica. 
Con esta base trataremos de verificar nuestra hipótesis: que las sentencias bilaterales tendrían un mejor encaje constitucional en los países de nuestro entorno jurídico que fórmulas como la cláusula canadiense. No solo porque permiten suavizar la objeción contramayoritaria, sino también porque constituyen una solución especialmente adecuada para superar el agravamiento que de la misma se ha producido por las frecuentes intromisiones de la justicia constitucional en las funciones del Poder Legislativo. Además, este tipo de pronunciamientos bilaterales, que transforman la enmienda de la inconstitucionalidad en un "proceso» colaborativo con el legislador, clarifica en cierta medida cuál ha de ser el papel que los tribunales constitucionales deben desempeñar dentro de un contexto de división de Poderes que ya no se corresponde con el existente en Europa antes de la Segunda Guerra Mundial.

Para concluir, veremos que esas sentencias bilaterales han servido también al Tribunal Constitucional español para evitar en ciertos casos esas intromisiones a las que nos referimos y que, por desgracia, se han producido en varias ocasiones.

\section{LA DIFICULTAD CONTRAMAYORITARIA}

Como hemos apuntado, todo nuestro análisis parte de una tensión o, mejor dicho, de una de las particulares manifestaciones de la tensión inherente al constructo de la democracia constitucional.

La expresión democracia constitucional designa un objeto complejo, una construcción de la razón (Salazar, 2006: 14) que surge de la integración de dos tradiciones del pensamiento político diferentes y, en buena medida, opuestas. Resumiendo de forma excesiva: mientras que la democracia pretende distribuir el poder político entre todos los individuos sometidos al mismo, el constitucionalismo aspira a limitar ese mismo poder en defensa de los derechos individuales. Del intento de fusionar ambas tradiciones ha surgido «la mejor forma de gobierno a la que pueden aspirar los seres humanos», afirmación a la que se adhiere quien está redactando estas líneas. Sin embargo, que estemos ante la que seguramente sea la mejor manera de organizar y distribuir el poder político de las hasta ahora implementadas no quiere decir que se halle libre de imperfecciones, siendo la principal la tensión generada al atribuir al demos el poder para adoptar las decisiones relativas a la organización de su convivencia al tiempo que pretenden salvaguardarse una serie de derechos individuales que actúen como límites frente a aquel. Esta tensión tiene múltiples concreciones, pero la que ahora nos interesa se manifiesta ya en el plano institucional y sería la que se da entre los órganos legislativos y los jueces constitucionales. Una tirantez conocida en la academia como dificultad $\mathrm{u}$ 
objeción contramayoritaria ${ }^{2}$ y cuya esencia puede sintetizarse en la siguiente pregunta: ¿por qué los jueces deberían poder anular las decisiones de los representantes elegidos democráticamente?

Sobre la objeción contramayoritaria se han vertido ríos de tinta. Baste aquí con referir la opinión mayoritaria: si bien es preciso que exista alguna fórmula de control que permita garantizar los derechos de los individuos frente a eventuales embates de la mayoría, sin embargo, en la medida en que son los jueces constitucionales quienes ostentan - por medio del control de constitucionalidad de las leyes - la «última palabra» en la toma de decisiones colectivas, el principio democrático podría resentirse ${ }^{3}$. Pero, añadimos nosotros, si la dificultad contramayoritaria parte de la idea de que un órgano con menor legitimidad democrática que un Parlamento — como los jueces constitucionales - puede anular las leyes emanadas de aquel, el problema se agrava considerablemente en la medida en que los tribunales constitucionales ya no se limitan a esa función meramente ablativa o expurgatoria del ordenamiento jurídico que, como nos recordara Rubio Llorente (1988), ya implicaba una alteración de este, pues "cualquier modificación de un sistema normativo cerrado crea reglas nuevas». En la actualidad, las cosas han ido más lejos, habiéndose desbordado ampliamente el rol de «legislador negativo» que Kelsen atribuyera al Tribunal Constitucional. Efectivamente, en muchos casos, y fundamentalmente bajo el pretexto de salvaguardar la vigencia de una ley, la justicia constitucional ha ido asumiendo tareas positivas, de creación de normas. Ya no solamente se contradice al legislador democrático cuando una ley se estima inconstitucional sino que, en ocasiones, incluso se usurpan sus funciones por medio de "sentencias intermedias ${ }^{4}$ ", esto es: "Aquellas que no se limitan a declarar la validez o nulidad de la ley impugnada, sino que introducen normas nuevas en el ordenamiento y, por tanto, suponen una actividad de legislación positiva» (Aja, 1998: 261). Se trata de la materialización de un riesgo que ya advirtiera el propio Kelsen (1988: 142-143) cuando recomendó abstenerse de recoger en las constituciones principios indeterminados como la libertad, la igualdad o la justicia, pues entendía que podían «jugar un papel

2 El término parece que fue acuñado por Alexander Bickel (1962) en The Least Dangerous Branch: The Supreme Court at the Bar of Politics.

3 Véase por todas la obra de Waldron, quien ha ido modulando sus posiciones al respecto desde su notorio Law and Disagreement, donde rechazaba cualquier forma de control de constitucionalidad de la ley por entender que esta se halla revestida de una especial majestuosidad, hasta conceder la necesidad de algún tipo de control de estas características para ciertos tipos de sociedades (2001).

4 Denominación atribuida en el Informe General de la VII Conferencia de Tribunales Constitucionales Europeos, celebrada en Lisboa en 1987. 
extremadamente peligroso precisamente en el campo de la justicia constitucional», ya que "podrían interpretarse las disposiciones de la Constitución que invitan al legislador a someterse a estos principios como directivas relativas al contenido de las leyes [...] y, en este caso, el poder del tribunal [constitucional] sería tal que habría que considerarlo simplemente insoportable».

Pues bien, cuando el debate sobre la objeción contramayoritaria parecía zanjado y esta se entendía como un mal menor inherente al sistema democrático-constitucional, la aparición de dos cuestiones diferentes, pero, a nuestro juicio, relacionadas por su potencialidad para superar la imperturbable tensión, ha reavivado la discusión. Nos referimos, por un lado, al surgimiento en países pertenecientes a la tradición jurídica del Commonwealth de diseños de ingeniería constitucional englobados bajo la denominación "constitucionalismo débil» o new Commonwealth constitutionalism que, para algunos autores (Gardbaum, 2013), podrían representar un nuevo paradigma de constitucionalismo donde ya no son los jueces constitucionales, sino los Parlamentos, los que ostentan la "última palabra» en la toma de decisiones colectivas, propiciando lo que destacados sectores doctrinales han calificado como un provechoso «diálogo interinstitucional» entre la justicia constitucional y los órganos representativos. Por otra parte, algunos tribunales constitucionales europeos han ido adoptando nuevas modalidades de pronunciamientos que, bajo el nombre de «sentencias bilaterales», permiten también, desde nuestro punto de vista, propiciar un diálogo interinstitucional al llamar a la colaboración del legislador en la enmienda de la inconstitucionalidad de la ley, atenuando también así la objeción contramayoritaria.

Veamos, pues, cuáles son las notas esenciales de ese «constitucionalismo débil» para, a continuación, analizar cómo surgieron y operan en el sistema constitucional canadiense, que fue pionero en implementarlas. Después nos ocuparemos de las llamadas «sentencias bilaterales» en Europa y de sus posibilidades dialógicas.

\section{CONSTITUCIONALISMO DIALÓGICO Y NEW COMMONWEALTH CONSTITUTIONALISM}

Al hablar de constitucionalismo dialógico lo primero que tenemos que hacer es determinar a qué nos estamos refiriendo, para así diferenciar este concepto y ponerlo en relación con otros similares como «constitucionalismo débil», «weak judicial review» o «new Commonwealth constitutionalism».

Según la RAE, el adjetivo «dialógico» significa: "perteneciente o relativo al diálogo, que presenta forma dialogada». Pero ¿diálogo entre quiénes? ¿Y sobre qué? El debate que se ha abierto acerca de lo que es o no diálogo en el 
constitucionalismo es prácticamente inconmensurable, por lo que nos conformaremos con decir que, cuando hablamos de diálogo, de constitucionalismo dialógico, nos referimos a la relación que, por medio de determinados mecanismos, se articula entre dos instituciones: los jueces constitucionales y los Parlamentos. Relación que versa sobre la determinación de la constitucionalidad de las leyes, de forma que cuando se detecte alguna disconformidad entre una ley y la norma cimera del ordenamiento, «ambos» órganos participen en el restablecimiento de dicha conformidad.

En estos términos, el concepto de constitucionalismo dialógico que vamos a manejar se aleja de propuestas como la de Gargarella (2013), que conecta el diálogo constitucional con una particular teoría de la democracia deliberativa. La noción de "diálogo" por la que hemos optado se asemeja más a la propuesta por Hogg y Bushell (1997) cuando afirman: «Where a judicial decision is open to legislative reversal, modification or avoidance, then it is meaningful to regard the relationship between the Court and the competent legislative body as a dialogue». Se trata de una idea que sintetiza especialmente bien el funcionamiento de la relación que se da en Canadá entre la justicia constitucional impartida por su Tribunal Supremo y el Poder Legislativo, y que nos sirve como punto de partida para determinar a continuación qué es lo que se entiende por «new Commonwealth constitutionalism» o «constitucionalismo débil».

Por contraposición a lo que ocurriría en los sistemas de «constitucionalismo fuerte», donde, en principio, son los jueces constitucionales quienes tienen la última palabra en el proceso de toma de decisiones colectivas y pueden, por lo tanto, «imponer al legislador ordinario sus puntos de vista acerca de cuestiones relativas a la concreción de los derechos sobre las que existen desacuerdos razonables» (Bayón, 2010: 354), las propuestas del constitucionalismo débil o dialógico "prometen terminar con las tradicionales objeciones democráticas a la revisión judicial, basadas en las débiles credenciales democráticas del Poder judicial, o los riesgos de que, al imponer la última palabra se afecte el sentido y objeto de la democracia constitucional» (Gargarella, 2013: 3). Así, la intervención de los jueces constitucionales en el marco de un sistema de constitucionalismo débil, referida como weak judicial review, serviría más bien para iniciar una suerte de diálogo institucional que incrementaría la calidad deliberativa de los procesos de decisión, «haciendo ver a la mayoría el peso de razones o puntos de vista que no ha sabido tomar en cuenta, o contradicciones y puntos débiles en la fundamentación de sus decisiones, forzándola de ese modo a reconsiderarlas, pero no necesariamente a abandonarlas» (Bayón, 2010: 354-355).

En las últimas décadas han aparecido varios diseños institucionales que podrían enmarcarse dentro de esta concepción del constitucionalismo. 
Para agruparlos, Gardbaum (2013) ha propuesto la categoría de «new Commonwealth constitutionalism», dentro de la cual se incluirían países que como Canadá (1982), Nueva Zelanda (1990), Reino Unido (1998), Australia (2004) o el estado de Victoria (2006) han introducido en sus constituciones novedosos mecanismos jurídicos. Entre las características esenciales de estos sistemas - que constituirían una especie de híbrido entre la tradicional supremacía del Parlamento propia del modelo británico y los Estados con constituciones rígidas y control de constitucionalidad—, estaría el haber introducido, mediante la inclusión de declaraciones de derechos y libertades con rango constitucional, formas débiles de control judicial de la constitucionalidad. Un weak judicial review donde, pese a que los jueces cuentan con un mandato constitucional para controlar la adecuación de las leyes a los contenidos constitucionales, existe algún tipo de mecanismo que permite al legislador recuperar la «última palabra» en la toma de decisiones colectivas.

Aquí nos limitaremos al estudio del caso canadiense, por haber sido este el primer ordenamiento en incorporar uno de estos mecanismos. En concreto, analizaremos la institución introducida en el art. 33 de su Constitución a través de la reforma operada en 1982. Mucho se ha debatido en los últimos tiempos acerca de este artificio jurídico, conocido como cláusula notwithstanding o "cláusula no-obstante», y su potencial para aliviar las tensiones que se dan entre la justicia constitucional y los Parlamentos democráticos. Veamos, pues, cómo funciona esta cláusula, de dónde proviene y cómo ha resultado su uso, antes de pasar a efectuar un balance sobre su capacidad para fomentar un diálogo constitucional entre el poder contramayoritario y los órganos legislativos.

\section{LA CLÁUSULA NOTWITHSTANDING DE LA CONSTITUCIÓN CANADIENSE}

El art. 33 de la Constitución canadiense establece lo siguiente:

Section 33.

(1) Parliament or the legislature of a province may expressly declare in an Act of the Parliament or of the legislature, as the case may be, that the Act or a provision thereof shall operate notwithstanding a provision included in section 2 or sections 7 to 15 of this Charter.

(2) An Act or a provision of an Act in respect of which a declaration made under this section is in effect shall have such operation as it would have but for the provision of this Charter referred to in the declaration. 
(3) A declaration made under subsection (1) shall cease to have effect five years after it comes into force or on such earlier dates as may be specified in the declaration.

(4) Parliament or the legislature of a province may re-enact a declaration made under subsection (1).

(5) Subsection (3) applies in respect of a re-enactment made under subsection (4).

Con base en esta disposición, el Parlamento federal de Canadá o las Asambleas legislativas provinciales pueden dictar leyes estableciendo expresamente que las mismas, o algunas de sus disposiciones, serán válidas aun cuando vulneren los derechos y libertades recogidos en los arts. 2 y 7 a 15 de la Constitución. Los únicos derechos fundamentales que quedan a salvo de esta posibilidad son los derechos lingüísticos (arts. 16-23), la libertad de circulación y de residencia (art. 6), los derechos políticos (art. 3), el derecho a la tutela judicial efectiva (art. 24) y la igualdad entre los dos sexos (art. 28).

Por lo que se refiere a sus efectos jurídicos, podemos distinguir en función de si se recurre a este mecanismo con carácter previo o posterior a un eventual pronunciamiento del Tribunal Supremo canadiense sobre la constitucionalidad de la disposición legislativa correspondiente. Así, aunque la doctrina tiende a utilizar indistintamente estas dos denominaciones (De Montalvo Jääskeläinen, 2012: 395), por un lado, podría hablarse de cláusula override, cuando la misma se utiliza después de un pronunciamiento estimatorio del Tribunal Supremo para salvar la constitucionalidad de la ley - lo que, de hecho, supone devolver al Legislativo la última palabra en la toma de decisiones colectivas- $\mathrm{y}$, por otro, podríamos referirnos a la cláusula notwithstanding en sentido estricto cuando el órgano legislativo recurre a ella a priori, es decir, antes incluso de que el Tribunal Supremo tenga la oportunidad de pronunciarse sobre la constitucionalidad de una ley. En este último supuesto lo que sucedería no es tanto que la última palabra sobre la adecuación de una ley a la Constitución vuelva de los jueces al Legislativo, sino que este último impediría la posibilidad de que aquellos se pronunciasen. Se estaría blindando la disposición legislativa frente a un eventual control de constitucionalidad.

Ahora bien, la utilización de este artificio jurídico no es tan sencilla como pudiera parecer, pues el recurso al mismo está expresamente sujeto a dos condiciones establecidas por el citado art. 33. En primer lugar, el apartado primero de dicho precepto obliga a que el órgano legislativo haga una referencia expresa a la utilización de la cláusula si quiere que esta produzca sus peculiares efectos, por lo que no es posible una cláusula no-obstante implícita. Esto permite demostrar que cuando el Legislativo recurre a este mecanismo es perfectamente consciente de lo que hace, al tiempo que se informa a la opinión 
pública sobre su excepcional utilización, lo que habría de promover el debate y la crítica. Así, este requisito hará más políticamente arriesgado aprobar una disposición que incluya una cláusula como la referida (Kahana, 2002: 231). En segundo lugar, el apartado tercero del art. 33 establece que la declaración de vulneración expresa que legítimamente puede incluir una ley tendrá una eficacia transitoria, limitando su vigencia a cinco años. En cualquier caso, el apartado cuarto de este mismo artículo permite prorrogar la declaración de vulneración expresa por otros cinco años tantas veces como estime oportuno, sin mayores límites. Pese a esto, la limitación temporal de validez tiene su razón de ser, pues al establecerse una revisión quinquenal se garantiza que durante ese tiempo haya tenido lugar un proceso electoral y, en consecuencia, un posible cambio de mayorías parlamentarias, con lo que se pone en manos del electorado un instrumento de control sobre la utilización de la cláusula (Hogg y Bushell, 1997: 84).

El origen de esta cláusula hay que situarlo en el contexto de la profunda reforma constitucional operada en 1982 y la introducción de la Carta canadiense de Derechos y Libertades. Como señala Hiebert (2001), esta reforma «representa el cambio más radical que se haya realizado nunca en la Constitución canadiense». Para comprender su trascendencia hay que saber que la independencia de Canadá respecto de Reino Unido se produjo precisamente en 1982 — dentro del denominado proceso de patriation - por medio de la Canada Act, una reforma constitucional que hubo de ser aprobada "por el Parlamento de Westminster en calidad de Parlamento imperial» (Castellà Andreu, 2001: 38). Hasta entonces, el principio constitucional básico imperante en Canadá fue el de la supremacía del Parlamento. Sin embargo, este principio será alterado por las enmiendas constitucionales introducidas en 1982, cuando el art. 52 de la Constitución canadiense proclame la supremacía normativa de esta, estableciendo expresamente que aquellas leyes incompatibles con las disposiciones constitucionales serán inaplicables e ineficaces ${ }^{5}$. Si a esto le sumamos lo establecido en el art. 24.1 de la Carta, según el cual «anyone whose rights or freedoms, as guaranteed by this Charter, have been infringed or denied may apply to a court of competent jurisdiction to obtain such remedy as the court considers appropriate and just in the circumstances», el resultado es que «los tribunales reciben el mandato explícito para interpretar los derechos de la Carta y garantizar su reparación cuando esta sea vulnerada» (Hiebert, 2001: 195).

5 "The Constitution of Canada is the supreme law of Canada, and any law that is inconsistent with the provisions of the Constitution is, to the extent of the inconsistency, of no force or effect». 
La metamorfosis que para el Estado canadiense supuso la aprobación de la Carta, con la incorporación de un control de constitucionalidad de la ley, fue especialmente compleja por la profunda diversidad existente entre sus provincias. Como señala Hiebert (ibid.), «inicialmente las provincias se opusieron a la idea de una declaración constitucional de derechos que afectara a sus respectivos ámbitos de decisión. No querían rendir cuentas a los tribunales y estaban preocupadas por el hecho de que una declaración constitucional de derechos ejerciera mayor efecto sobre sus propias competencias que sobre las del Parlamento central». En consecuencia, fue necesario negociar fórmulas que permitieran conjugar la existencia de una Constitución rígida y suprema con el mantenimiento del poder último de decisión en manos de las provincias en lo relativo a sus respectivas competencias. Así, la opción de compromiso fue la de introducir la cláusula «no-obstante» del art. 33, sobre la cual podemos afirmar, siguiendo a Chacón Piqueras (2001), que nació con el «claro propósito de proteger la autonomía de los Parlamentos provinciales», siendo más el resultado de las negociaciones políticas que tuvieron lugar para sacar adelante la Carta que la concreción de una teoría diseñada con el propósito de salvar la dificultad contramayoritaria. Leeson (2001) resulta especialmente elocuente al apuntar: "The particular version that emerged in November 1981 and was ultimately enacted in 1982 had more to do with the raw politics of bargaining and chance phone calls late at night than with reasoned debate about what might constitute a rational compromise between democracy and constitutional law». Ahora bien, esto no implica que estemos ante una solución improvisada. Por el contrario, tanto la Carta de 1982 como la cláusula «no-obstante» tienen sus precedentes legislativos en la Canadian Bill of Rights de 1960 y en algunas declaraciones de derechos provinciales como la Charte des droits et libertés de la personne du Québec de 1975, el Saskatchewan Human Rights Code de 1979 o la Alberta Bill of Rights de 1980. Ahora bien, como ha destacado Chacón Piqueras (2001), la diferencia fundamental entre estos precedentes y la vigente Carta de Derechos y Libertades reside en que ahora «la protección que otorga a los derechos su constitucionalización se ve alterada por un mecanismo que posibilita que normas infraconstitucionales, sólo declarándolo formalmente, la contradigan».

En cuanto al uso de la cláusula notwithstanding en estos 36 años, hemos de destacar que el recurso a la misma ha sido prácticamente anecdótico. El Parlamento federal nunca la ha incorporado a ninguna ley. Por su parte, de entre los parlamentos provinciales solo el de Quebec se ha servido de este mecanismo con alguna frecuencia, lo que seguramente haya estado influido por ciertas particularidades. En este sentido no podemos omitir el dato de que la Ley Constitucional de 1982 — por medio de la cual Canadá asume el control total sobre su ordenamiento jurídico frente a Reino Unido- fue aprobada 
por todas las provincias excepto Quebec, es decir, que a esta última le fue impuesta una Constitución federal que nunca ratificó. Apuntado esto es más fácil comprender por qué ha sido precisamente la provincia que no insistió en la incorporación de la cláusula no-obstante la que ha terminado utilizándola con mayor asiduidad; y es que cuando la Constitución entró en vigor la Asamblea de Quebec adoptó la Loi sur la Loi Constitutionelle de 1982, en virtud de la cual se incorporaba una cláusula derogatoria a todas sus leyes vigentes y a las que se dictasen a partir de aquel momento, como forma de protesta frente a la imposición constitucional.

Más allá de esta anécdota, sí que existen algunos casos concretos donde se ha recurrido a la cláusula para asegurar la validez de leyes específicas frente a la interpretación jurisprudencial de determinados derechos constitucionales. Así, la Asamblea legislativa de la provincia de Saskatchewan recurrió a la cláusula derogatoria en la SGEU Dispute Settlement Act de 1984 para obviar una resolución de la Corte de Apelación de la provincia y salvar la validez de una norma que pretendía poner fin a una huelga de empleados públicos, aunque más adelante el Tribunal Supremo señaló que la citada ley no vulneraba los derechos de la Carta ${ }^{6}$. Otros ejemplos que podríamos considerar más acordes con su propósito original los vuelve a protagonizar la provincia de Quebec, destacando especialmente el caso Ford v. Quebec (1988), donde el Tribunal Supremo canadiense anuló una norma quebequesa por la que se imponía el uso exclusivo del francés en los letreros comerciales colocados tanto en el interior como en el exterior de los comercios, por considerar que esta disposición vulneraba la libertad de expresión reconocida en el art. 2 de la Carta de Derechos y Libertades de 1982. Para salvar dicha norma, la Asamblea legislativa de Quebec aprobó la Loi modifiant la Charte de la langue française, L.Q. 1988, en virtud de la cual se volvía a exigir el uso exclusivo de la lengua francesa (ahora ya solo para los letreros comerciales colocados en el exterior de los locales) y se blindaba la misma recurriendo a la cláusula no-obstante. También Quebec ha utilizado el mecanismo derogatorio en otras ocasiones para mantener los privilegios otorgados a las confesiones católica y protestante en materia de educación (Chacón Piqueras, 2001: 217). Por último, cabría mencionar el uso que hizo de la cláusula notwithstanding la provincia de Alberta con el objetivo de salvaguardar su Marriage Act de 2002 — con la que pretendía restringir la noción de matrimonio exclusivamente a los enlaces entre personas de distinto sexo- frente a una eventual declaración de inconstitucionalidad. Sin embargo, como señala De Montalvo (2012), la inclusión de la cláusula por parte de la Asamblea de Alberta no tuvo mayor repercusión, ya que el Tribunal

$6 \quad$ RWDSU v. Saskatchewan (1987) 1 S.C.R. 460. 
Supremo declaró que la definición del matrimonio era una cuestión que correspondía exclusivamente al Estado central.

Como vemos, el uso que de la cláusula no-obstante se ha hecho en la práctica ha sido mínimo. Ahora bien, ¿cabe por ello concluir que su incorporación a la Constitución canadiense ha sido un fracaso? Recordemos que lo que pretendíamos analizar en este trabajo no es la frecuencia con que se ha recurrido a este mecanismo, sino las posibilidades que ofrece para fomentar un diálogo entre la justicia constitucional y el legislador. En este sentido, cabe extraer las siguientes conclusiones.

En primer lugar, la mera existencia de esta institución permite superar la comúnmente denominada dificultad contramayoritaria en la medida en que sustrae la "última palabra» a los jueces constitucionales para devolvérsela al Poder Legislativo. Sin embargo, este (re)empoderamiento del Parlamento no parece que haya derivado en un atropello masivo y sistemático de los derechos de las minorías, lo que seguramente ayuda a evitar tanto los requisitos que su utilización exige como los elevados costes políticos asociados que implica, circunstancias que permiten explicar la escasa utilización práctica de la cláusula. En segundo lugar, no parece que el escasísimo recurso a este mecanismo constituya un problema. Seguramente no fue diseñado para ser utilizado con asiduidad, sino para que el legislador responda a los tribunales cuando no esté convencido de la argumentación sobre la que se sostiene la declaración de inconstitucionalidad y tenga razones de peso que esté dispuesto a exponer en público, sin sonrojarse, para oponerse a la interpretación que de los derechos y libertades han hecho los jueces. Por tanto, el diálogo interinstitucional al que nos venimos refiriendo se produce antes de que el legislador recurra a la cláusula, pues precisamente el uso de esta pone fin —en algún momento es preciso tomar decisiones, pues los órganos constitucionales no pueden estar pasándose la responsabilidad de un lado a otro eternamente- a ese diálogo. Ahora bien, el hecho de que el mecanismo exista seguramente fomenta el que el legislador se anime a modificar la ley teniendo en cuenta los argumentos dados por los tribunales, pues sabe que el esfuerzo merecerá la pena ya que, si esta fuera invalidada en una segunda ocasión, siempre podrá hacer uso de la cláusula no-obstante. De igual manera, es probable que los jueces se muestren más deferentes con el legislador cuando la ley que enjuician constituya un segundo intento de aquel por ajustarla a la constitucionalidad, pues serán conscientes de que una nueva oposición sin tener suficientemente en cuenta las razones aducidas por el Legislativo podrá acabar suponiendo el rechazo de su interpretación. Por último, no podemos sino coincidir con Bayón (2010) y Chacón Piqueras (2001) en que no parece razonable poder blindar una ley ex ante, esto es, utilizar la cláusula con la pretensión de evitar un pronunciamiento de los tribunales acerca de la constitucionalidad de la disposición que 
está tratando de protegerse. Es obvio que esta posibilidad no promueve sino que impide el diálogo entre ambas instituciones.

\section{LAS POSIBLES TÉCNICAS DIALÓGICAS DEL CONTROL DE CONSTITUCIONALIDAD EN EUROPA}

El «sistema europeo» de control de constitucionalidad no surgirá hasta más de un siglo después que el estadounidense ${ }^{7}$, modelo que desde un principio manifestó el temor a que las mayorías parlamentarias pudieran eventualmente conculcar los derechos de las minorías (Madison, 1787). Por su parte, la preocupación principal de los revolucionarios franceses fue asegurar un poder sin límites para el Parlamento en cuanto que órgano representativo de la «voluntad general», con lo que inicialmente «ni siquiera el principio de la supremacía constitucional era un principio ampliamente aceptado» (Salazar, 2006). No será hasta el siglo xx cuando, ideado teóricamente por Kelsen e implementado por primera vez en la Constitución austriaca de 1920, aparezca un esquema de control de constitucionalidad característicamente europeo. En contraste con el sistema americano, Kelsen propuso concentrar dicha potestad en un órgano creado para garantizar que el legislador se ajustase a las reglas de producción normativa constitucionalmente establecidas. La Constitución debía ser objeto de protección por representar la estabilidad del Estado, pero no porque tuviera un contenido normativo particular, pues, de hecho, este podía ser alterado en cualquier momento a través de los procedimientos de revisión previstos en la propia norma. En otras palabras, lo que Kelsen defendía no era una concepción axiológica de la Constitución.

Partiendo de estas premisas, el Tribunal Constitucional quedaba configurado como un órgano supremo e independiente, con capacidad para anular las normas que estimase disconformes con la Constitución. Se trataría de una institución que, lejos de integrarse dentro del Poder Judicial, tendría una naturaleza más propia de «legislador negativo», pues, en palabras del propio Kelsen (1988: 130): «Anular una ley es dictar una norma general; porque la anulación de una ley tiene el mismo carácter de generalidad que su producción y no es, por así decirlo, sino producción con signo negativo y, por lo tanto, una función legislativa». Como vemos, se atribuye a este órgano un papel respecto del cual resulta perfectamente predicable la objeción contramayoritaria que surgiera en Estados Unidos, pues también aquí la justicia constitucional puede contradecir la voluntad de los representantes populares, oponiéndose

$7 \quad$ Inaugurado a nivel federal con la Sentencia Marbury vs. Madison, 5 U.S. 137 (1803). 
a las decisiones de la mayoría. Plenamente consciente de esta crítica, Kelsen fundamentó su respuesta a la misma en la idea de concebir la Constitución como un instrumento "técnico», diseñado para garantizar la estabilidad y la «paz política» en el interior del Estado (ibid.), que permitiría a las minorías políticas impugnar las decisiones mayoritarias sin salirse del circuito institucional, canalizando así los conflictos sociales a través del derecho.

Sin embargo, la actividad de los tribunales constitucionales se ha ido apartando progresivamente del papel de «legislador negativo» para adoptar con cierta frecuencia decisiones positivas, de creación de normas, más propias de las funciones que ha de desempeñar el legislador democrático, lo que supone tanto un riesgo para la división de Poderes como un «agravamiento» de la dificultad contramayoritaria «clásica».

[...] en las últimas décadas, de manera habitual, los Tribunales Constitucionales vienen adoptando un tipo de sentencias, conocidas con diferentes denominaciones según los países (interpretativas, aditivas, manipulativas, sustitutivas, constructivas, apelativas, etc.), que los configuran como legislador positivo, porque la sentencia constitucional no se limita a suprimir el precepto legal contrario a la Constitución, sino que incorpora una nueva norma al ordenamiento. Este tipo de sentencias, que puede encontrar precedentes aislados más o menos lejanos, resulta un fenómeno nuevo por la intensidad que presenta en las últimas décadas (Aja, 1998: 259-260).

Veamos cuáles han sido las razones fundamentales que han permitido este desvío del modelo originario. En primer lugar, las constituciones que surgieron o se reformaron en Europa occidental tras la Segunda Guerra Mundial introdujeron todo un entramado de principios y valores como la dignidad humana, la justicia, la libertad o la igualdad, junto con extensos catálogos de derechos basados en los mismos. El carácter vago o ambiguo de muchos de estos preceptos hace que los mismos resulten susceptibles de diversas interpretaciones, lo que permite efectuar un profundo $-\mathrm{y}$, en no pocas ocasiones, controvertido - examen de una legislación que, además, es cada vez más abundante como consecuencia del amplio intervencionismo de los Poderes públicos, resultado de la consolidación del modelo de Estado democrático y social (ibid.: 260). Estos cambios estructurales, sumados a un "principio o criterio de mantenimiento de la ley» (Jiménez Campo, 1997: 45), basado seguramente en la «especial dignidad democrática» que a esta se atribuye, han propiciado el que cada vez se haya ido recurriendo en menor medida a la declaración de nulidad de las disposiciones legislativas para, por medio de la interpretación secundum Constitutionem de la disposición enjuiciada, tratar de salvaguardar a toda costa la pervivencia de la ley en el ordenamiento jurídico. Un proceso al que sin duda también ha contribuido «la distinción del objeto 
de control de constitucionalidad entre precepto o enunciado legal y norma o normas que aquél contiene», permitiendo la «multiplicación de sentencias con efectos positivos, porque permite cambiar las normas sin modificar el precepto» (Aja, 1998: 261).

En determinados casos, la declaración de nulidad puede no reparar - $\mathrm{e}$ incluso empeorar - la situación causada por una disposición que se estima inconstitucional (pensemos, por ejemplo, en las consecuencias que podría tener la declaración de nulidad de partidas presupuestarias correspondientes a ejercicios económicos ya cerrados). Sin embargo, creemos que esto no justifica el uso tan habitual que actualmente se hace de las llamadas «sentencias intermedias», pronunciamientos que pueden ser de muy diverso tipo pero que, en su mayoría, aun resultando formalmente desestimatorios, «tienen siempre, cualquiera que sea la formulación de su fallo, un alcance materialmente estimatorio, en la medida en que, de modo directo o indirecto, excluyen o niegan la constitucionalidad de una norma deducible del enunciado legal a partir de los cánones hermenéuticos establecidos con carácter general» (Jiménez Campo, 1997: 45). La problemática que este tipo de sentencias constitucionales plantea se ve agravada por el hecho de que no suelen encontrar asidero en derecho positivo, siendo los propios tribunales constitucionales los que, por medio de una interpretación muy laxa de sus propias leyes reguladoras - cuando no actuando al margen o en franca oposición a lo que estas establecen- han ido introduciendo por la vía de los hechos este tipo de pronunciamientos.

Finalmente, resulta conveniente que aludamos a una última distinción entre «sentencias unilaterales» y «sentencias bilaterales». Aquellas que hasta ahora hemos venido denominando como «intermedias» (sentencias interpretativas, aditivas, manipulativas, sustitutivas, constructivas, apelativas, etc.) pueden también ser consideradas como «sentencias unilaterales» por cuanto «remedian inmediatamente la inconstitucionalidad, modificando la norma considerada inconstitucional» (Aja, 1998: 277). Por el contrario, en algunos países europeos han ido surgiendo tipos de pronunciamientos que parte de la doctrina ha calificado como «sentencias bilaterales», donde lo que tiene lugar es una «reparación mediata» (Jiménez Campo, 1997: 53-66) de la inconstitucionalidad, es decir, donde la reparación se produce mediante la intervención de órganos distintos al Tribunal Constitucional, el cual se limita a emitir la declaración de inconstitucionalidad. En concreto, lo que requerirá esta reparación mediata será la intervención del legislador y, provisionalmente, mientras esta no se produzca, la del Poder Judicial. Pues bien, nuestra tesis pasa por afirmar que la dificultad contramayoritaria se ve agravada por las «sentencias unilaterales», con las que no solo se contradice la voluntad mayoritaria — como ocurre cuando simplemente se anula una disposición legislativa-, sino que el teóricamente «legislador negativo» va más allá, llegando a entrometerse en 
funciones propias de los órganos legislativos. Lo contrario ocurriría, creemos, con las llamadas "sentencias bilaterales», de algunos de cuyos ejemplos más significativos ahora nos ocuparemos. En estos casos, la «última palabra» en la toma de decisiones públicas no es tanto que no recaiga en la justicia constitucional como que se comparte con el legislador, propiciándose así un diálogo interinstitucional que convierte la reparación de la ley inconstitucional en un «proceso» más que en un acto unilateral. De este modo, la tradicional tensión entre jueces constitucionales y legisladores a la que venimos refiriéndonos se ve profundamente suavizada, si es que no totalmente eliminada. Entre estos mecanismos «bilaterales» destacan especialmente la posibilidad de diferir la nulidad en el tiempo y la llamada inconstitucionalidad sin nulidad o «mera incompatibilidad", por lo que ahora nos ocuparemos de analizar cada una de estas dos modalidades de pronunciamientos en el marco jurídico en que han surgido, que son el austriaco y el alemán, respectivamente. Después estudiaremos las posibilidades de utilización que estos tipos de «sentencias bilaterales» tienen en el ordenamiento jurídico español.

\section{LA ANULACIÓN DIFERIDA Y EL REENVÍO LEGISLATIVO EN AUSTRIA}

Uno de los países de nuestro entorno jurídico donde existe uno de los mecanismos que creemos susceptible de generar una suerte de diálogo o interacción interinstitucional entre la justicia constitucional y el Parlamento es la República de Austria. En efecto, el Tribunal Constitucional austriaco tiene atribuida desde la Constitución de 1920 la posibilidad no solo de anular leyes, sino de diferir en el tiempo la entrada en vigor de dicho efecto anulatorio.

Antes de analizar en profundidad este mecanismo conviene hacer una aclaración. Hemos dicho que el Tribunal Constitucional en Austria está facultado para «anular» (aufheben) las disposiciones legislativas que estime inconstitucionales, que no es lo mismo que decir que está habilitado para «declarar su nulidad». Esta diferencia es relevante para entender por qué el tipo de pronunciamiento que vamos a estudiar ha sido posible en este país desde un primer momento, pero no en otros ordenamientos jurídicos próximos. En abstracto, los conceptos de «nulidad» $\mathrm{y}$ «anulabilidad» son dos categorías dogmáticas aparentemente claras, que obedecen a tradiciones jurídicas diversas. Puestas en relación con los efectos de las sentencias recaídas en los procesos de control de constitucionalidad de las leyes, ambas implican la expulsión del precepto inconstitucional del ordenamiento jurídico. Sin embargo, sus efectos temporales son diferentes. Así, la declaración de nulidad tendría efectos ex tunc, es decir, la norma jurídica afectada por la misma estaría aquejada de un vicio ab initio que el Tribunal Constitucional se limitaría señalar en una sentencia puramente «declarativa», con lo que los efectos de la inconstitucionalidad se 
retrotraerían al momento en que la norma fue promulgada. Por el contrario, la «anulabilidad» implicaría, de modo similar a lo que ocurre con la derogación (Abschaffung), la pérdida de vigencia de la disposición derogada y los efectos de la sentencia constitucional, que ya no sería declarativa sino constitutiva, serían ex nunc: se producirían a partir del momento en que se anulase el acto o la norma de que se trate. Ahora bien, lo cierto es que en la práctica estas categorías nunca producen plenamente los efectos que de ellas se predican, pues siempre están matizados por los distintos ordenamientos. En el caso de España, donde la sanción que lleva aparejada la declaración de inconstitucionalidad es la nulidad (art. 39.1 LOTC), la teórica retroacción ex tunc está limitada, por razones de seguridad jurídica, por la propia LOTC, que en su art. 40.1 establece lo siguiente: "Las sentencias declaratorias de la inconstitucionalidad de Leyes, disposiciones o actos con fuerza de Ley no permitirán revisar procesos fenecidos mediante sentencia con fuerza de cosa juzgada en los que se haya hecho aplicación de las Leyes, disposiciones o actos inconstitucionales». Una limitación de la nulidad que es acto seguido excepcionada para los casos de normas penales o administrativas sancionadoras más favorables: «Salvo en el caso de los procesos penales o contencioso-administrativos referentes a un procedimiento sancionador en que, como consecuencia de la nulidad de la norma aplicada, resulte una reducción de la pena o de la sanción o una exclusión, exención o limitación de la responsabilidad». Igualmente, aquellos ordenamientos que, como el austriaco, establecen la derogación como efecto de la declaración de inconstitucionalidad matizan también los efectos exclusivamente ex nunc.

El Tribunal Constitucional austriaco (TCA), pues, «anula» y no «declara la nulidad» de las leyes que estima inconstitucionales, como se deriva de los arts. 140.3 («el tribunal únicamente podrá anular una ley como anticonstitucional») y 140.5 («el fallo del Tribunal Constitucional por el que se anule una ley como anticonstitucional, obliga al Canciller federal o al Gobernador regional competente a publicar sin demora la derogación») de su Constitución, y tal y como ha sido reconocido desde muy pronto por el propio $\mathrm{TCA}^{8}$. Anulación que la Constitución de 1920 (CA) completa atribuyendo al Tribunal Constitucional en su art. 140.5 la posibilidad de diferir en el tiempo los efectos de esta derogación, es decir, de establecer una vacatio de hasta un

8 Vid. STCA 1491/1932: «Una ley que se oponga a la Constitución no es inválida ni, por tanto, absolutamente nula, sino un acto que, a pesar de ser inconstitucional, era jurídicamente vinculante hasta su eventual derogación». 
máximo de dieciocho meses ${ }^{9}$ por medio de la cual retrasar la entrada en vigor de la derogación de aquellas normas que hubiera declarado inconstitucionales. Pese a que la redacción de este precepto parece contemplar dicha posibilidad como un recurso excepcional, lo cierto es que «el Tribunal constitucional austriaco ha hecho un uso muy amplio de esta facultad en un doble sentido: por un lado, utilizándola con gran frecuencia y, por otro, limitándose a invocar el art. 140.5 CA como único fundamento de la misma» (González Beilfuss, 2000: 186).

En caso de que el TCA opte por diferir en el tiempo el inicio de los efectos de la derogación, mientras no se cumpla el plazo fijado por la sentencia la norma inconstitucional permanece vigente, es decir, sigue siendo de aplicación a todos los casos salvo al llamado Anlassfall (art. 140.7 CA), el supuesto de hecho que ha dado origen a la declaración de inconstitucionalidad - he aquí una aplicación retroactiva que modula los efectos pro futuro tradicionalmente predicados de la anulación-; es más, la norma declarada inconstitucional y que sigue siendo aplicada no puede volver a ser impugnada por ningún procedimiento (Aja, 1998: 280).

Aceptar que una ley inconstitucional siga produciendo efectos es más fácil de asumir en Austria que en países como España o Alemania, donde, por su tradición jurídica, resultaría especialmente chocante que una norma que ha sido declarada inconstitucional (y, por tanto, nula) continúe produciendo efectos. Ahora bien, pese a que el recurso a la anulación diferida podría estar regulado con mayor precisión — favoreciendo, por ejemplo, la previsibilidad de este tipo de pronunciamientos por medio de una regulación que concretase los supuestos en que el Tribunal puede hacer uso de esta potestad-, lo cierto es que por medio de esta vacatio se evitan diversos problemas como los generados por las sentencias aditivas o los que puede ocasionar el vacío normativo causado por la derogación de normas inconstitucionales. Además, el hecho de que esta posibilidad se encuentre positivizada permite que la legitimidad del TCA no se resienta cuando opte por recurrir a la misma.

Esta figura nos resulta especialmente interesante, pues la idea que late detrás de la misma es la de dar un plazo al legislador para que sea este el que enmiende la norma declarada inconstitucional. De este modo, aunque sigue siendo el Tribunal Constitucional el que mantiene la «última palabra» a la hora de decidir sobre la constitucionalidad de las leyes - y suya es la decisión de recurrir o no a este mecanismo-, lo cierto es que, siempre que el mismo sea utilizado y que el legislador actúe dentro del plazo que le ha sido concedido

9 El plazo máximo inicial, ampliado en sucesivas reformas constitucionales, era de seis meses. 
en la sentencia, lo que ocurrirá en la práctica será que el TCA se limitará a identificar la incompatibilidad de la norma enjuiciada con la Constitución, siendo el legislador quien tendrá en su mano remediar tal situación. Se trata de una fórmula que, a nuestro juicio, permite articular una suerte de reenvío legislativo, propiciando en cierto modo que el Tribunal Constitucional actúe, en palabras de Gargarella (2013), como un poder de control «orientado a llamar la atención — tanto de los legisladores como de la ciudadanía — respecto de normas todavía imperfectas a fin de procurar una paulatina mejora de la producción legislativa y promover un valioso diálogo interinstitucional».

Pese a esto, nos parece importante insistir en la trascendental diferencia que existe entre mecanismos como la derogación diferida y otros como la cláusula no-obstante canadiense, pues mientras que por medio del primero es el Tribunal Constitucional el que apela al legislador para que este participe en el restablecimiento de la constitucionalidad de la ley, el segundo constituye la clave de bóveda de un diseño institucional diferente, donde lo que se pretende es algo mucho más radical: devolver al legislador la «última palabra» en la toma de decisiones públicas. Ahora bien, lo que resulta innegable es que ambos mecanismos permiten una subsiguiente intervención del legislador a la correspondiente declaración de inconstitucionalidad, haciendo que el restablecimiento de la constitucionalidad se convierta más en un "proceso» interinstitucional que en el resultado de una decisión unilateral.

\section{LA INCONSTITUCIONALIDAD SIN NULIDAD EN ALEMANIA}

Otra modalidad de pronunciamiento dentro de las llamadas «sentencias bilaterales» son las sentencias declarativas de inconstitucionalidad que no llevan aparejada la nulidad, también conocidas como de «mera incompatibilidad». Tienen su origen en la práctica del Tribunal Constitucional Federal alemán (TCF), que las dictó durante años al margen de lo establecido en el art. 78 de su ley reguladora (en adelante, BVerfGG), donde se establece que el Tribunal debe «declarar nulas» las leyes inconstitucionales. Pese a esto, la práctica ha terminado por ser positivizada, si bien es cierto que de un modo confuso e incompleto, pues la reforma de la BVerfGG en 1970 optó por incorporar una mención a la figura de la inconstitucionalidad sin nulidad en dos preceptos que «regulan aspectos tangenciales como la publicación de las sentencias o su alcance temporal en el ámbito penal» (González Beilfuss, 2000: 200), quedando inmodificada la rígida vinculación establecida por el ya mencionado art. 78.

Declarar que una disposición legislativa es «meramente incompatible» con la Ley Fundamental de Bonn ha permitido al TCF evitar tanto los problemas 
técnicos que acarrea una declaración de nulidad ${ }^{10}$ como respetar la libertad de configuración del legislador ordinario.

En cuanto a sus consecuencias jurídicas, nunca ha estado totalmente claro cuál es el régimen jurídico aplicable durante el período de tiempo que va desde la declaración de inconstitucionalidad hasta que se aprueba una nueva ley. Weber (1998) apunta a que «la consecuencia jurídica de la declaración de incompatibilidad consiste en que la norma inconstitucional sigue manteniéndose en el entramado normativo y que las normas jurídicas anteriores a su entrada en vigor no reviven. La norma inconstitucional soporta, sin embargo, una prohibición de aplicación (Anwendungssperre) que se retrotrae al momento de la colisión normativa». Esto quiere decir que se reconocería como la consecuencia jurídica habitual de los fallos de inconstitucionalidad sin nulidad la inaplicación de la norma inconstitucional y la interrupción de los procedimientos en que sea aplicable, extendiéndose de este modo la prohibición de aplicar el régimen inconstitucional del Anlassfall — del caso que da origen a la sentencia declarativa - a los denominados casos paralelos (Parallelfälle), es decir, a los demás supuestos de hecho pendientes o que pueden plantearse durante el período interino y a los que en principio sería aplicable el régimen jurídico declarado inconstitucional. En efecto, la BVerGE 37, 217 (261) optó por esta solución al establecer que «la nulidad y la mera inconstitucionalidad tienen los mismos efectos tanto respecto al pasado como al futuro", lo que, como señala González Beilfuss (2000), resulta desconcertante si pensamos en que, precisamente, «esta figura tenía su origen en los problemas planteados por los fallos típicamente anulatorios», pero que puede explicarse por la enorme influencia que el dogma de la nulidad ex tunc tiene en el país germano. Sin embargo, y para mayor confusión, la propia Sentencia 37, 217/261 «reconoció también de forma expresa que, excepcionalmente, las normas inconstitucionales podían seguir siendo aplicadas durante dicho periodo». Así, parecería que la inaplicación de la norma inconstitucional y la interrupción de aquellos procedimientos donde esta fuera aplicable serían la regla general, mientras que la aplicación del régimen inconstitucional constituiría una excepción. Sin embargo, lo cierto es que esto no ha quedado claro, pues el Tribunal nunca ha desarrollado criterios inteligibles sobre los casos en que haya de aplicarse

10 Como nos recuerda Jiménez Campo (1997): «La declaración de nulidad es sencillamente inutilizable en pronunciamientos que no cancelen o supriman enunciados legales o fragmentos de los mismos (pronunciamientos, por ejemplo que operen reducciones o ampliaciones de su ámbito de aplicación) y tampoco cabe acudir a ella cuando el resultado ablativo en nada repare, o aun empeore, la situación inconstitucional». 
la teórica regla general o la supuesta excepción. Para mayor inri, ahora que el Tribunal ha comenzado a pronunciarse con más frecuencia sobre los efectos de las declaraciones de inconstitucionalidad sin nulidad, mayoritariamente ordena que el régimen jurídico inconstitucional siga aplicándose durante el período interino (González Beilfuss, 2000: 273). Esta postura parece la más lógica si pensamos que los efectos de su alternativa - la inaplicación de la normativa inconstitucional y la interrupción de los procedimientos en que hubiera sido aplicable - serían muy similares a los que se producen a consecuencia de un pronunciamiento meramente ablativo.

En definitiva, la aplicación transitoria de la normativa inconstitucional puede no resultar especialmente agradable, sobre todo cuando se trate de una legislación discriminatoria. No obstante, nos parece un precio razonable a pagar por evitar una intromisión por parte del Tribunal Constitucional en las funciones propias del legislador. Este último ha sido quien ha traspasado los límites que la Constitución le impone y habrá de ser él, una vez apercibido públicamente y bajo la lupa del resto de operadores jurídicos y de la sociedad en su conjunto, el que enmiende dicho error.

\section{LAS POSIBILIDADES DE DIÁLOGO INTERINSTITUCIONAL Y LOS MECANISMOS DE EQUILIBRIO EN ESPAÑA}

La Constitución española de 1978 (en adelante, CE) establece un sistema de control «concentrado» de constitucionalidad de las leyes. Ahora bien, a diferencia del modelo kelseniano original, donde «la eliminación del precepto inconstitucional no despliega sus efectos hacia el pasado» (Díaz Revorio, 2001: 149), el sistema español se halla claramente condicionado por el dogma de la nulidad ex tunc, de forma que el «intérprete supremo de la Constitución» no anula sino que declara la nulidad de las normas inconstitucionales. Tan profundamente arraigada está esta idea en nuestro país que la LOTC apuesta inequívocamente por vincular declaración de inconstitucionalidad con nulidad en su art. 39.1: "Cuando la sentencia declare la inconstitucionalidad, declarará igualmente la nulidad de los preceptos impugnados [...]». Sin embargo, esta opción legislativa no parece que venga constitucionalmente impuesta, y coincidimos con la opinión de Díaz Revorio (ibid.) cuando señala que «la ley podría permitir efectos diferentes a los de la nulidad con efectos $e x$ tunc, al menos en ciertos supuestos». Con todo, la opción por la que ha apostado nuestro legislador no deja lugar a dudas, estableciendo un férreo binomio entre inconstitucionalidad y nulidad que, en no pocas ocasiones, ha resultado excesivamente rígido, obligando a nuestro Tribunal Constitucional (TC) a romper el vínculo entre inconstitucionalidad y nulidad con la adopción de 
«sentencias bilaterales». En efecto, lo cierto es que nuestro Tribunal Constitucional, al igual que sus homólogos europeos, se ha visto forzado en determinadas circunstancias a responder de diferentes maneras a lo que, realmente, son diversos supuestos de inconstitucionalidad de las leyes ${ }^{11}$. Por ello, cuando el TC se ha encontrado con modalidades de inconstitucionalidad frente a las cuales la pura y simple declaración de nulidad no resultaba adecuada para el restablecimiento de la constitucionalidad, ha recurrido a pronunciamientos intermedios de distinto tipo. Así, desde tan temprano como la STC 5/81, de 13 de febrero, nuestro Tribunal Constitucional ha adoptado repetidamente «sentencias interpretativas ${ }^{12}$ ». Frente a otros supuestos, el TC ha adoptado «sentencias manipulativas», entendiendo por tales aquellas que «declaran la inconstitucionalidad de una norma parte del contenido normativo derivado conjuntamente del texto impugnado" (ibid.: 158-159). Desde nuestro punto de vista, las sentencias interpretativas no implican tanto una vulneración del binomio impuesto por la LOTC como una forma de soslayarlo, una maniobra posible gracias al cambio que se produce en el objeto del enjuiciamiento constitucional al sustituirse la disposición por la norma. Pese a esto, lo que no ofrece duda es que con muchos de estos pronunciamientos el TC excede la función nomofiláctica (propia de un legislador negativo) para, al imponer una única interpretación de las disposiciones, ejercer una función nomotética, de selección de opciones (propia de un legislador positivo). Así, la objeción contramayoritaria se ve agravada por una práctica que, si bien ha tratado de justificarse en la deferencia hacia la obra del legislador, lo cierto es que, especialmente en aquellos casos en que las sentencias «se apartan abiertamente del tenor literal de la ley enjuiciada, no sólo invaden la competencia del poder

11 Como apunta Jiménez Campo (1997): «La inconstitucionalidad de la ley es expresión bajo la que cobijamos realidades diversas, diversidad que no sólo procede del distinto modo en que una regla legal puede entrar en contradicción con la Constitución, sino también de otros factores, como son, en especial, el carácter de la ley inconstitucional o el tipo de vicio que la afecta».

12 «Las llamadas en parte de la doctrina Sentencias interpretativas, esto es, aquellas que rechazan una demanda de inconstitucionalidad o, lo que es lo mismo, declaran la constitucionalidad de un precepto impugnado en la medida en que se interprete en el sentido que el Tribunal Constitucional considera como adecuado a la Constitución, o no se interprete en el sentido (o sentidos) que considera inadecuados, son, efectivamente, un medio al que la jurisprudencia constitucional de otros países ha recurrido para no producir lagunas innecesarias en el ordenamiento, evitando, al tiempo, que el mantenimiento del precepto impugnado pueda lesionar el principio básico de la primacía de la Constitución. Es, en manos del Tribunal, un medio lícito, aunque de muy delicado y difícil uso [...]» (STC 5/81, de 13 de febrero, FJ 6). 
legislativo, sino que deterioran la posición del poder de reforma constitucional al restringir sus opciones» (Punset, 2014: 95).

Ante este panorama, se ha reclamado la utilización de alternativas menos invasivas de las funciones del Parlamento. El propio TC — que ha manifestado en más de una ocasión ser consciente de la importancia de respetar el papel del legislador ${ }^{13}$ - ha adoptado sentencias donde se declara la mera incompatibilidad de una disposición legislativa con algún precepto constitucional, o pronunciamientos donde la eficacia de la nulidad queda diferida en el tiempo por medio de un plazo que el Tribunal otorga al legislador para que enmiende la constitucionalidad de la ley. Así, en el fallo de la temprana STC 45/1989, de 20 de febrero, optó por declarar la mera inconstitucionalidad del art. 4.2 de la Ley 44/1978, de 8 de septiembre, del Impuesto sobre la Renta de las Personas Físicas, en cuanto que el mismo no preveía para los miembros de la unidad familiar, «ni directamente ni por remisión, posibilidad alguna de sujeción separada", imponiendo discriminatoriamente a estos la sujeción conjunta a dicho impuesto. Igualmente, en la STC 195/1998, de 1 de octubre, el Tribunal optó de nuevo por no declarar la nulidad de la Ley 6/1992, de 27 de marzo, por la que se declara Reserva Natural a las Marismas de Santoña y Noja, pues, pese a la invasión competencial del legislador estatal, la ausencia de legislación autonómica que regulase la cuestión hizo conveniente "precisar el alcance que debemos dar al fallo de esta resolución, ya que, en las actuales circunstancias, anudar a la declaración de inconstitucionalidad la nulidad inmediata de la Ley 6/1992 podría producir graves perjuicios a los recursos naturales de la zona objeto de controversia» (FJ 5). Como vemos, el argumento esgrimido para no declarar la nulidad de la norma se basa en evitar la aparición de una laguna jurídica en el ordenamiento, que hubiera tenido unas consecuencias más graves que las derivadas de mantener vigente una ley estatal invasora de competencias autonómicas. Tampoco resulta complicado encontrar ejemplos en los que el TC ha optado por diferir la nulidad de algún precepto inconstitucional. Tal es el caso de la STC 208/1999, en cuyo fallo se decide:

13 «Debe insistirse una vez más en que el control de la constitucionalidad de las leyes debe ejercerse por este Tribunal de forma que no se impongan constricciones indebidas al poder legislativo y se respeten sus legítimas opciones políticas. Por lo demás, como venimos señalando, el cuidado que este Tribunal ha de observar para mantenerse dentro de los límites del control del legislador democrático debe extremarse cuando se trata de aplicar preceptos generales e indeterminados» (STC 136/2011, de 13 de septiembre, FJ 12.b). 
[...] estimar parcialmente los recursos de inconstitucionalidad y, en consecuencia, declarar inconstitucional la cláusula «en todo o en parte del mercado nacional», en la medida en que desconoce las competencias ejecutivas de la legislación estatal sobre defensa de la competencia atribuidas a las Comunidades Autónomas recurrentes en sus respectivos Estatutos, difiriendo su nulidad hasta el momento en que, establecidos por la ley estatal los criterios de conexión pertinentes, puedan las Comunidades Autónomas ejercitarlas.

Como vemos, la falta de cobertura legal de este tipo de sentencias no ha impedido que nuestro Tribunal Constitucional haga uso de las mismas en aquellos casos en que el recurso a la pura y simple declaración de nulidad generaría una situación menos acorde con la Constitución que la vigencia de una norma inconstitucional. Ahora bien, se plantea un problema evidente, pues estas dos posibilidades no solo no encuentran respaldo en la legislación sino que, ahora sí, vulneran lo expresamente dispuesto en el art. 39 de la LOTC — precepto que, sensu contrario, prohíbe expresamente toda medida que separe inconstitucionalidad y nulidad-. El atrevimiento del Tribunal Constitucional ha tenido consecuencias positivas. Sin embargo, que uno de los órganos que diariamente se encargan de sostener nuestro Estado de derecho se vea ante la disyuntiva de o bien quebrantar la ley o bien causar una situación de inconstitucionalidad aún más grave resulta cuando menos perturbador. Y es que, con la disolución del binomio inconstitucionalidad-nulidad, son numerosas las consecuencias jurídicas de gran calado que, en detrimento del principio de seguridad jurídica, quedan indeterminadas, a la libre discrecionalidad del Tribunal Constitucional.

En el año 2005 el legislador planteó un proyecto de reforma de la Ley Orgánica 2/1979, del Tribunal Constitucional ${ }^{14}$, por medio del cual se pretendía, entre otras cosas, disolver el férreo vínculo establecido en el art. 39 LOTC entre inconstitucionalidad y nulidad, introduciendo tanto la posibilidad de dictar sentencias de mera incompatibilidad como de diferir en el tiempo los efectos de la nulidad. La exposición de motivos de dicho proyecto hablaba de acometer «reformas sustanciales en relación con los procesos de control de constitucionalidad», delimitando «con mayor precisión cuáles son los efectos de las sentencias en los procesos de constitucionalidad». En efecto, el art. 39.1, tal y como estaba proyectado en dicha iniciativa, hubiera establecido lo siguiente: «Cuando la sentencia declare la inconstitucionalidad, declarará igualmente la nulidad de los preceptos impugnados o cuestionados. No obstante, motivadamente y para preservar los valores e intereses que la

14 El texto original del proyecto se encuentra en el Boletin Oficial de las Cortes Generales. Congreso de los Diputados, serie A, n. ${ }^{\circ}$ 60-1, de 25 de noviembre de 2005. 
Constitución tutela, la sentencia podrá declarar únicamente la inconstitucionalidad o diferir los efectos de la nulidad por un plazo que en ningún caso será superior a tres años».

A esta hipotética redacción del apartado primero del art. 39 le fueron planteadas dos enmiendas ${ }^{15}$ que abogaron por mantener la redacción original del precepto al entender, respectivamente, que diferir a un momento posterior la nulidad de una norma que ya ha sido declarada inconstitucional «abre un panorama para los aplicadores de las normas, en primer término, y para la ciudadanía, en términos generales, confuso y vulnerable», y que facultar al Tribunal Constitucional para suplir lagunas normativas «es atribuirle facultades legislativas, lo que es inconstitucional», o que "el plazo de inconstitucionalidad con nulidad diferida es demasiado amplio, generando una enorme inseguridad jurídica». También se presentó una enmienda en la que se mantenía la nulidad diferida pero se eliminaba la posibilidad de emitir pronunciamientos de mera incompatibilidad, lo que se justificaba aduciendo que «la introducción de que la declaración de inconstitucionalidad de una norma pueda [ir] independizada de su nulidad, de forma absoluta y permanente, no encuentra apoyo en el artículo 161 de la Constitución». Finalmente —y sin que los diarios de sesiones puedan arrojar ninguna luz al respecto, pues parece que la negociación fue despachada en el seno de la correspondiente ponencia-, en el informe que se elevó a la Comisión Constitucional sobre el proyecto de ley ${ }^{16}$ desaparece la modificación propuesta y el tenor original del art. 39 se mantiene, llegando así inalterado a lo que será la Ley Orgánica 6/2007, de 24 de mayo, por la que se modifica la Ley Orgánica 2/1979, de 3 de octubre, del Tribunal Constitucional. Una decisión que hemos de lamentar, pues mantiene la prohibición de flexibilizar los efectos de las sentencias recaídas en procesos de inconstitucionalidad, dificultando a nuestro Tribunal Constitucional el recurso a unas modalidades de pronunciamiento que, a nuestro juicio, son necesarias tanto para poder hacer frente a las diversas causas de inconstitucionalidad como para que el Tribunal encuentre un mejor acomodo dentro de un nuevo contexto de división de Poderes donde no puede seguir siendo el legislador negativo que ideara Kelsen, pero tampoco puede ocupar una función política de selección de opciones, que ha de corresponder exclusivamente a los representantes democráticamente elegidos por los ciudadanos.

15 Estas enmiendas y sus respectivas justificaciones pueden consultarse en el Boletin Oficial de las Cortes Generales. Congreso de los Diputados, serie A, n. ${ }^{\circ}$ 60-7, de 23 de febrero de 2006.

16 Boletin Oficial de las Cortes Generales. Congreso de los Diputados, serie A, n. ${ }^{\circ}$ 60-9, de 5 de diciembre de 2006. 


\section{CONCLUSIONES}

El punto de partida de este trabajo ha sido la pregunta de por qué unos órganos con menor legitimidad democrática tienen constitucionalmente atribuida la potestad de anular las decisiones de aquellos otros que han sido democráticamente elegidos. Como hemos visto, esta paradoja parecería ser un resultado inherente a las democracias constitucionales, un «mal menor» sin solución aparente. Sin embargo, los países de la antigua Commonwealth dieron sin pretenderlo - pues lo que en realidad buscaban era modular un principio típicamente británico como el de la supremacía del Parlamento-, con una fórmula que, desde nuestro punto de vista, permite efectivamente salvar esa dificultad, introduciendo alguna forma de control judicial de constitucionalidad. Así, lo que ha ocurrido en países como Canadá es que, al pretenderse la constitucionalización de determinados derechos y libertades y la atribución a los jueces y tribunales de la capacidad para enjuiciar las leyes, no se ha llegado hasta el modelo propio de las democracias estadounidense y europeas, donde la consecuencia de ese control de la constitucionalidad se traduce en el otorgamiento a los jueces constitucionales de la última palabra en la toma de decisiones públicas, germen de aquella objeción contramayoritaria. Por el contrario, el intento de establecer una constitución rígida y algún tipo de mecanismo judicial que garantice su supremacía en países tributarios de la tradición jurídica británica de alguna manera se ha "quedado corto», dando lugar a un modelo intermedio, el «new Commonwealth constitutionalism», que tiene como consecuencia inesperada la de superar la objeción contramayoritaria por medio de mecanismos que, al estilo del art. 33 de la Constitución canadiense, permiten que el legislador democrático recupere o, mejor dicho, mantenga la última palabra en la toma de decisiones. Estos artificios jurídicos han sido aplaudidos por importantes sectores doctrinales, que los han considerado un avance en cuanto que susceptibles de generar un diálogo interinstitucional entre tribunales y Parlamentos útil para perfeccionar y depurar el proceso de producción normativa. No obstante, creemos que fórmulas como la canadiense son factibles en países pertenecientes a una tradición jurídico-constitucional muy característica, ajena a la imperante en Europa continental. Además, nuestra cultura jurídica ha generado también algunos mecanismos para equilibrar la relación entre tribunales constitucionales y Parlamentos, permitiendo suavizar la dificultad contramayoritaria. Una dificultad que, en las últimas décadas, se ha visto agravada a consecuencia de un preocupante intrusismo por parte de la justicia constitucional en las funciones legislativas. El legislador negativo - merecedor de la objeción contramayoritaria aunque perfectamente democrático- ha llegado en ciertos casos a ocupar el papel propio de un legislador positivo, algo tan intolerable como peligroso. Una perversión potenciada por 
la imposibilidad de restablecer adecuadamente, a través de la anulación o la declaración de nulidad, una constitucionalidad que, en la práctica, puede haberse visto conculcada por razones muy diversas que requerirán soluciones alternativas para su enmienda. A este respecto, los hechos se han impuesto sobre lo legalmente previsto, apareciendo modalidades de pronunciamientos que no solo permiten evitar intromisiones en las funciones propias del Legislativo, sino que además sirven para suavizar la dificultad contramayoritaria en la medida en que devuelven la responsabilidad al legislador, haciendo que este participe en el «proceso» de enmienda de la constitucionalidad de las leyes.

Creemos también que la utilización de estas sentencias bilaterales permite clarificar el rol que la justicia constitucional debe ocupar dentro de una nueva forma de entender la división de poderes, donde ya no puede limitarse a actuar simplemente como legislador negativo, pero tampoco puede convertirse en legislador positivo. En este sentido, siempre que un tribunal constitucional haya recurrido a una sentencia unilateral (interpretativa, manipulativa, etc.), podría en su lugar haber dictado una bilateral que hubiera sido una respuesta mucho más respetuosa con el papel del legislador democrático. Sentencias que, además, son también susceptibles de propiciar un diálogo entre ambas instituciones que, si bien es cierto que se produce dentro de un marco jurídico-institucional diferente, creemos que se adecúa mejor a nuestra tradición jurídica de lo que lo haría la mera importación de mecanismos como la cláusula canadiense, los cuales probablemente generarían un fuerte rechazo en nuestros ordenamientos. Pero apostar por los pronunciamientos bilaterales implica sobre todo abogar por su positivización, pues no es propio de un Estado de derecho que se precie forzar a que sus instituciones, para poder cumplir cabalmente con la función que les ha sido encomendada, se vean obligadas a soslayar, cuando no a vulnerar frontalmente, la legalidad vigente, minando así su legitimación de ejercicio. La legalización de este tipo de decisiones, unida a una toma de conciencia clara por parte de la justica constitucional de cuál ha de ser su papel institucional, de los límites dentro de los cuales es legítimo el ejercicio del control de la constitucionalidad de una ley en una democracia representativa, podría ayudar a clarificar cuál es el ámbito de actuación de unos órganos a los que se atribuye una función constitucional absolutamente esencial en nuestros días.

\section{Bibliografía}

Aja, E. (ed.) (1998). Las tensiones entre el Tribunal Constitucional y el Legislador en la Europa actual. Barcelona: Ariel. 
Bayón, J. C. (2010). Democracia y derechos: problemas de fundamentación del constitucionalismo. En M. Carbonell y L. García (eds.). El canon neoconstitucional (pp. 282-355). Madrid: Trotta.

Bickel, A. (1962). The Least Dangerous Branch: The Supreme Court at the Bar of Politics. New Haven: Yale University Press.

Castellà Andreu, J. M. (2001). La evolución político-constitucional de Canadá. En E. Mitjans y J. M. Castellá (coords.). Canadá: introducción al sistema político y jurídico (pp. 27-55). Barcelona: Publicacions de la Universitat de Barcelona.

Chacón Piqueras, C. (2001). Las cláusulas «no obstante» y limitativa general de derechos de la Carta canadiense de derechos y libertades de 1982. En E. Mitjans y J. M. Castellá (coords.). Canadá: introducción al sistema político y jurídico (pp. 211-226). Barcelona: Publicacions de la Universitat de Barcelona.

De Montalvo Jääskeläinen, F. (2012). Las cláusulas notwithstanding y override del constitucionalismo canadiense. Teoría y Realidad Constitucional, 30, 387-409. Disponible en: https://doi.org/10.5944/trc.30.2012.7013.

Díaz Revorio, F. J. (2001). Las sentencias interpretativas del Tribunal Constitucional: significado, tipología, efectos y legitimidad: análisis especial de las sentencias aditivas. Valladolid: Lex Nova.

Ferreres Comella, V. (2007). Justicia constitucional y democracia. Madrid: Centro de Estudios Políticos y Constitucionales.

Gardbaum, S. (2013). The New Commonwealth Model of Constitutionalism. Cambridge: Cambridge University Press.

Gargarella, R. (2013). El nuevo constitucionalismo dialógico frente al sistema de los frenos y contrapesos. Revista Argentina de Teoría Jurídica, 14 (2), 1-32. Disponible en: https://bit.ly/2LC0f1x.

González Beilfuss, M. (2000). Tribunal Constitucional y reparación de la discriminación normativa. Madrid: Centro de Estudios Políticos y Constitucionales.

Hiebert, J. L. (2001). Los efectos de la Carta de Derechos y Libertades en la política canadiense. En E. Mitjans y J. M. Castellá (coords.). Canadá: introducción al sistema político y jurídico (pp. 195-209). Barcelona: Publicacions de la Universitat de Barcelona.

Hogg, P. W. y Bushell, A. (1997). The Charter Dialogue between Courts and Legislatures (Or Perhaps the Charter of Rights Isn't Such a Bad Thing after All). Osgoode Hall Law Journal, 35 (1), 75-124.

Jiménez Campo, J. (1997). Qué hacer con la ley inconstitucional. En La sentencia sobre la constitucionalidad de la ley: Actas de las II Jornadas de la Asociación de Letrados del Tribunal Constitucional. Madrid: Tribunal Constitucional; Centro de Estudios Políticos y Constitucionales.

Kahana, T. (2002). Understanding the Notwithstanding Mechanism. University of Toronto Law Journal, 52, 221-274. Disponible en: https://doi. org/10.2307/825966.

Kelsen, H. (1988). La garantía jurisdiccional de la constitución (la justicia constitucional). En H. Kelsen. Escritos sobre la democracia y el socialismo (pp. 109-155). Madrid: Editorial Debate. 
Leeson, H. (2001). The Notwithstanding Clause: A Paper Tiger? En P. Howe y P. H. Russell (eds.). Judicial Power and Canadian Democracy. Montreal [etc.]: McGill-Queen's University Press.

Madison, J. (1787). The Federalist Papers: $n .^{\circ}$ 10. Disponible en: https://bit.ly/1L3 guuV.

Punset, R. (2014). Potestades normativas y forma de gobierno. Madrid: Centro de Estudios Políticos y Constitucionales.

Rubio Llorente, F. (1988). La jurisdicción constitucional como forma de creación del Derecho. Revista Española de Derecho Constitucional, 22, 9-51.

Salazar, P. (2006). La democracia constitucional. Una radiografía teórica. México D.F.: Fondo de Cultura Económica.

Waldron, J. (2001). Law and Disagreement. Oxford: Oxford University Press.

- (2006). The core of the case against Judicial Review. The Yale Law Journal, 115, 1346-1360. Disponible en: https://doi.org/10.2307/20455656.

Weber, A. (1998). Alemania. En E. Aja (ed.) Las tensiones entre el Tribunal Constitucional y el Legislador en la Europa actual (pp. 53-87). Barcelona: Ariel. 